\title{
The Search For A Dog-Free Portfolio: Why Unions Matter To Investors
}

Carol M. Boyer, Long Island University, CW Post, USA

Stephen J. Ciccone, University of New Hampshire, USA Philip Swicegood, Wofford College, USA

\begin{abstract}
This paper uses portfolio filtering and weighting research to create a dog-free portfolio. The variables used to create the dog-free portfolio include level of unionization and book-to-market. The filtered and weighted portfolio is averaging 47 basis points alpha per month from 1991-2007 over the benchmark S\&P500, outperforming in 60.8\% of the months. Using annual data, the portfolio averages 603 basis points alpha from 1991-2007 over the benchmark S\&P500, outperforming $82.4 \%$ of the time.
\end{abstract}

Keywords: performance, alpha, unions, book-to-market, portfolio filtering

\section{INTRODUCTION}

nstead of trying to pick specific firms to beat the S\&P 500, our approach is to eliminate those firms from the S\&P 500 that are expected to underperform. The simplicity of our dog-free sample is that it includes only two filters - book-to-market and unions. Thus, we include only value firms (the top half by book-tomarket) without unions. The rationale for choosing value firms stems from research by Rosenberg, Reid, and Lanstein (1985) who use book-to-market to obtain abnormal performance by buying stocks with a high book-tomarket price and selling stocks with a low book-to-market ratio. Fama and French (1992) also find that stocks with high book-to-market stocks tended to outperform the market.

In light of the recent difficulties of the heavily unionized auto industry, we feel this paper is a timely look at the relationship between unionized firms and stock returns. Numerous academic studies have studied unionization and stock returns (Bronars and Deere, (1991), Danthine and Donaldson, (2002), Merz and Yashiv (2006). According to Bronars, Deere and Tracy (1994), unions have a strong negative effect on profitability in both manufacturing and nonmanufacturing. They suggest that this effect is due to strong evidence that higher union coverage reduces capital investments by the firm. Furthermore, Ruback and Zimmerman (1984) find that, on average, unionization is related to a decrease in equity value. By examining union election returns, they find that equity declines by an average of $3.8 \%$ when the union wins an election and also declines by $1.3 \%$ when the union loses an election. These findings lead us to examine what would happen if we took the S\&P 500 and removed firms with unions.

We combined the findings on book-to-market and unions to create a dog-free portfolio where instead of picking a select number of firms that are intended to beat the S\&P 500, we seek to take the S\&P 500 and subtract the dogs. Another unique aspect of our study is that we utilize a fundamental weighted approach in contrast to the market value weighted approach. Research has shown that capital weighted indexes inadvertently overweight overpriced stocks and underweight underpriced stocks, but you don't know which is which without hindsight (Arnott, 2005, and Seigel, 2006). Specifically, we utilize a sales weighted and market value weighted approach, which are fundamental weighted approaches.

The implications of our research are that we have developed a strategy that beats the S\&P. In addition, we shed light on the timely issue of unionization as well as showing the importance of value investing. The paper also compares our strategy under value weighting and sales weighting. 


\section{DATA AND METHODOLOGY}

The Center for Research in Security Prices' database is used to obtain return and market value data. Compustat is used to obtain book value and sales data. The market-to-book ratio is computed as price times shares divided by the book value of equity. To help ensure the ratio is known by investors, the ratio is determined in the fiscal year prior to the year of the returns. Union data is hand-collected data set of active unions in the S\&P 500 .

Firms comprising the actual S\&P 500 Index are the starting point for the sample. To be considered for inclusion, the necessary data from CRSP and Compustat must be available. As a result of the data requirements, some S\&P 500 firm-year observations are missing. As a validity check, the annual S\&P 500 returns computed herein are compared to the annual returns of the actual S\&P 500 Total Return Index. The S\&P 500 Total Return Index includes dividends in the return calculation.

Table 1 presents the results of this comparison. The table indicates that S\&P 500 of this study generates a significantly lower return versus that of the actual S\&P 500. While the difference is statistically significant, the economic significance is rather small. The mean annual difference is only $-0.29 \%$. The lower return of the starting sample of S\&P 500 firms is also conservative. Any excess return generated by the dog-free portfolio must compensate for this lower return. Thus, despite some missing firms, the starting sample of S\&P 500 firms in this study is considered satisfactory.

Table 1: Sample S\&P 500 Returns Versus Actual S\&P 500 Returns

\begin{tabular}{|c|c|c|c|}
\hline Year & Actual S\&P 500 Annual Return & Sample S\&P 500 Annual Return & Difference Actual - Sample \\
\hline 1991 & 0.3047 & 0.3234 & -0.0187 \\
\hline 1992 & 0.0762 & 0.0775 & -0.0013 \\
\hline 1993 & 0.1008 & 0.0905 & -0103 \\
\hline 1994 & 0.0132 & 0.0178 & -0.0046 \\
\hline 1995 & 0.3758 & 0.3776 & -0.0036 \\
\hline 1996 & 0.2296 & 0.2332 & -0.0014 \\
\hline 1997 & 0.3336 & 0.3350 & -0.0034 \\
\hline 1998 & 0.2858 & 0.2892 & -0.0051 \\
\hline 1999 & 0.2104 & 0.2155 & -0.0060 \\
\hline 2000 & -0.0910 & -0.0851 & -0.0020 \\
\hline 2001 & -0.1189 & -0.1169 & -0.0061 \\
\hline 2002 & -0.2210 & -0.2149 & 0.0002 \\
\hline 2003 & 0.2869 & 0.2867 & -0.0002 \\
\hline 2004 & 0.1088 & 0.1090 & -0.0030 \\
\hline 2005 & 0.0491 & 0.0521 & 0.0015 \\
\hline 2006 & 0.1579 & 0.1565 & -0.0039 \\
\hline 2007 & 0.0549 & 0.0588 & $-0.0029^{* *}$ \\
\hline Mean & 0.1269 & 0.1298 & $-0.0030^{* * *}$ \\
\hline Median & 0.1088 & 0.1090 & 0.0103 \\
\hline Maximum & 0.3758 & 0.3776 & -0.0187 \\
\hline Minimum & -0.2210 & -0.2149 & \\
\hline
\end{tabular}

$* * *, * *, *$ Indicates the difference is statistically significant with $99 \%, 95 \%$, or $90 \%$ confidence, respectively, using a t-Test for the mean and a Wilcoxon Signed-Ranks Test for the median.

From the starting sample of S\&P 500 firms, the dog-free portfolio is obtained. First, firms are sorted into two halves based on market-to-book ratio. All firms in the upper half are considered growth firms and are removed from the portfolio. All firms with unionized labor are then removed. The firms remaining in the portfolio are thus union-free, value firms.

The sample period begins in 1991 and extends through 2007. Monthly returns within a calendar year are compounded to obtain annual returns. To minimize transactions costs, the portfolio is rebalanced at the beginning of the calendar year. Firms in the portfolio at the beginning of the year are then kept in the portfolio until the end of the year. 
The dog-free portfolio return is computed using two different weighting schemes. The first is marketweighted, which is the weighting scheme of the actual S\&P 500 Index. The other weighting method is sales. Weights are determined at the beginning of the calendar year and kept constant throughout the year. Weights are computed by first summing the market values or sales figures of all sample firms. A firm's individual weight is determined by dividing that firm's market value or sales figure by the total. Dog-free portfolio returns are then compared to the returns of the actual S\&P 500 Total Return Index.

\section{RESULTS}

Using a value weighted approach, the mean return of the dog-free portfolio is $2.54 \%$ higher than the S\&P 500 , while the median return is $4.04 \%$ higher (Table 2). The results indicate the superiority of the dog-free S\&P. In the year 2000, the return of the dog-free portfolio was $27.94 \%$ higher, while in the year 1999, the dog-free portfolio underperformed the S\&P 500 by $11.90 \%$. During the 17-year time period studied, the dog-free portfolio outperforms the S\&P 500 in 10 of the 17 years.

Table 2: Value Weighted Dog-Free Portfolio Returns versus Actual S\&P 500 Returns

\begin{tabular}{|c|c|c|c|}
\hline Year & Actual S\&P 500 Annual Return & Dog-Free VW Annual Return & Difference Dog-Free - Actual \\
\hline 1991 & 0.3047 & 0.2271 & -0.0776 \\
\hline 1992 & 0.0762 & 0.0699 & -0.0063 \\
\hline 1993 & 0.1008 & 0.1690 & 0.0682 \\
\hline 1994 & 0.0132 & -0.0043 & -0.0175 \\
\hline 1995 & 0.3758 & 0.3939 & 0.0181 \\
\hline 1996 & 0.2296 & 0.2700 & 0.0404 \\
\hline 1997 & 0.3336 & 0.3201 & -0.0135 \\
\hline 1998 & 0.2858 & 0.1675 & -0.1183 \\
\hline 1999 & 0.2104 & 0.0914 & -0.1190 \\
\hline 2000 & -0.0910 & 0.1884 & 0.2794 \\
\hline 2001 & -0.1189 & -0.0567 & 0.0622 \\
\hline 2002 & -0.2210 & -0.1686 & 0.0524 \\
\hline 2003 & 0.2869 & 0.3741 & 0.0872 \\
\hline 2004 & 0.1088 & 0.2109 & 0.1021 \\
\hline 2005 & 0.0491 & 0.1541 & 0.1050 \\
\hline 2006 & 0.1579 & 0.2096 & 0.0517 \\
\hline 2007 & 0.0549 & -0.0275 & -0.0824 \\
\hline Mean & 0.1269 & 0.1523 & 0.0254 \\
\hline Median & 0.1088 & 0.1690 & 0.0404 \\
\hline Maximum & 0.3758 & 0.3939 & 0.2794 \\
\hline Minimum & -0.2210 & -0.1686 & -0.1190 \\
\hline
\end{tabular}

If a portfolio manager were to use a sales weighted approach, the dog-free portfolio outperforms the S\&P 500 by $6.03 \%$ on average and the median outperformance is $4.92 \%$ (Table 3). The results also confirm the superiority of the sales weighting approach. In the year 2000, using a sales weighted approach, the dog-free portfolio outperforms by $41.24 \%$ and underperforms in 1999 by $16.61 \%$. During the 17 -year study, the sales weighted dog-free portfolio outperforms the S\&P 500 in 14 of the 17 years.

This paper uses portfolio filtering and weighting research to create a dog-free portfolio. We back-tested the data for 17 years, broke the results down on a monthly basis, and examined down-market periods (refer to Table 4) The filtered and weighted portfolio is averaging 47 bps alpha per month from 1991-2007 over the benchmark S\&P500, outperforming in $60.8 \%$ of the months. On the risk side, Beta $=0.97$, while correlation $=83.2 \%$ versus the S\&P500. In months when the S\&P500 is down, the portfolio has 39 bps alpha, has 65.9\% correlation with S\&P500, and outperforms in 59.4\% of the months. Using annual data, the portfolio averages 603 bps alpha from 1991-2007 over the benchmark S\&P500, outperforming $82.4 \%$ of the time. This portfolio is re-set once per year, so trading is minimal, providing low transaction costs and optimal tax benefits. Our back-testing timeframe of 17 years (19912007) is broad enough to cover several market cycles to ensure robustness of our approach. 
Table 3: Sales Weighted Dog-Free Portfolio Returns versus Actual S\&P 500 Returns

\begin{tabular}{|c|c|c|c|}
\hline Year & Actual S\&P 500 Annual Return & Dog-Free SW Annual Return & Difference Dog-Free - Actual \\
\hline 1991 & 0.3047 & 0.3259 & 0.0212 \\
\hline 1992 & 0.0762 & 0.1254 & 0.0492 \\
\hline 1993 & 0.1008 & 0.1944 & 0.0936 \\
\hline 1994 & 0.0132 & 0.0328 & 0.0196 \\
\hline 1995 & 0.3758 & 0.3870 & 0.06112 \\
\hline 1996 & 0.2296 & 0.2915 & 0.0058 \\
\hline 1997 & 0.3336 & 0.3394 & -0.1418 \\
\hline 1998 & 0.2858 & 0.1440 & -0.1661 \\
\hline 1999 & 0.2104 & 0.0443 & 0.4124 \\
\hline 2000 & -0.0910 & 0.3214 & 0.1724 \\
\hline 2001 & -0.1189 & 0.0535 & 0.0007 \\
\hline 2002 & -0.2210 & -0.2203 & 0.1960 \\
\hline 2003 & 0.2869 & 0.4829 & 0.1405 \\
\hline 2004 & 0.1088 & 0.2493 & 0.1632 \\
\hline 2005 & 0.0491 & 0.2123 & 0.0694 \\
\hline 2006 & 0.1579 & 0.2273 & -0.0831 \\
\hline 2007 & 0.0549 & -0.0282 & $0.0603^{*}$ \\
\hline Mean & 0.1269 & 0.1872 & $0.0492^{* *}$ \\
\hline Median & 0.1088 & 0.2123 & 0.4124 \\
\hline Maximum & 0.3758 & 0.4829 & -0.1661 \\
\hline Minimum & -0.2210 & -0.2203 & \\
\hline
\end{tabular}

Table 4: All markets versus Down Markets

\begin{tabular}{|c|c|c|c|c|c|c|}
\hline \multicolumn{7}{|c|}{ Returns in Down Market } \\
\hline & $\mathbf{A}$ & B & $\mathbf{C}$ & $\mathbf{D}$ & & \\
\hline & Actual & Weight only & Filter only & Filter + Weight & $\mathbf{C}-\mathbf{A}$ & $\mathbf{D}-\mathbf{A}$ \\
\hline & S\&P Return & Adj return & Adj return & Adj return & Difference & Difference \\
\hline Mean & -0.0324 & -0.0283 & -0.0290 & -0.0285 & 0.0034 & 0.0039 \\
\hline Median & -0.0243 & -0.0214 & -0.0239 & -0.0233 & -0.0005 & 0.0024 \\
\hline Std Dev & 0.0265 & 0.0305 & 0.0318 & 0.0393 & 0.0210 & 0.0296 \\
\hline Max & -0.0036 & 0.0249 & 0.0264 & 0.0466 & 0.0673 & 0.0895 \\
\hline Min & -0.1446 & -0.1408 & -0.1776 & -0.1680 & -0.0385 & -0.0787 \\
\hline avg annual correl & -0.3888 & -0.3391 & -0.3478 & -0.3415 & 0.7552 & 0.6592 \\
\hline \multicolumn{6}{|l|}{ D > A: \%superior } & 0.5942 \\
\hline \multicolumn{7}{|c|}{ Returns in All Markets } \\
\hline & $\mathbf{A}$ & $\mathbf{B}$ & $\mathbf{C}$ & D & & \\
\hline & Actual & Weight only & Filter only & Filter + Weight & $C-A$ & $\mathbf{D}-\mathbf{A}$ \\
\hline & S\&P Return & Adj return & Adj return & Adj return & Difference & Difference \\
\hline Mean & 0.0098 & 0.0117 & 0.0120 & 0.0145 & 0.0022 & 0.0047 \\
\hline Median & 0.0129 & 0.0145 & 0.0158 & 0.0175 & 0.0016 & 0.0058 \\
\hline Std Dev & 0.0388 & 0.0394 & 0.0408 & 0.0456 & 0.0196 & 0.0253 \\
\hline Max & 0.1144 & 0.1131 & 0.1153 & 0.1358 & 0.1104 & 0.1167 \\
\hline Min & -0.1446 & -0.1408 & -0.1776 & -0.1680 & -0.0420 & -0.0787 \\
\hline mean annual correl & 0.1175 & 0.1408 & 0.1437 & 0.1742 & 0.0262 & 0.0567 \\
\hline \multicolumn{6}{|l|}{ D > A: \%superior } & 0.6078 \\
\hline
\end{tabular}

\section{CONCLUSION}

This paper uses portfolio filtering and weighting research to create a dog-free portfolio. The variables used to create the dog-free portfolio include level of unionization and book-to-market ratios. The filtered and weighted portfolio is averaging 47 bps alpha per month from 1991-2007 over the benchmark S\&P500, outperforming in $60.8 \%$ of the months. Using annual data, the portfolio averages 603 bps alpha from 1991-2007 over the benchmark S\&P500, outperforming $82.4 \%$ of the time. 


\section{AUTHOR INFORMATION}

Carol Boyer is an Assistant Professor of Finance at Long Island University - CW Post campus in Brookville, NY. She received her Ph.D. from Florida State University. Some of her publications include The Cambridge Journal of Economics, Advances in Investment Analysis and Portfolio Management, and Managerial Finance. She has presented research papers at the European FMA, EFA, Decision Sciences Institute, FMA, and the ABN AMRO International IPO Conference.

Stephen J. Ciccone is currently the Chair of the Accounting and Finance Department and an Associate Professor of Finance at the University of New Hampshire's Whittemore School of Business. He received a Ph.D. in Business Administration (Finance) from Florida State University in 2000. He also holds a Bachelor's and a Master's degree in accounting from the University of Florida. He worked as an auditor for Arthur Andersen from 1994 to 1996 and has been a CPA since 1995. His research has appeared in multiple finance and accounting journals. In 2006, he received the Whittemore School's Outstanding Researcher award.

Philip Swicegood teaches Finance at Wofford College. He holds a Ph.D. in Finance from Florida State University, an M.B.A. in Finance from the University of Texas-Austin, and a B.S. degree in Finance and Philosophy from Liberty University. Philip directs The Broad River Group LLC, a real estate investment firm. He has worked in the banking industry for the Office of the Comptroller of the Currency, and has served as a business consultant for companies in the U.S., Russia, China, Vietnam, and Poland. Philip conducts seminars for HighMark Inc., a nonprofit consulting firm that provides business training in developing countries.

\section{REFERENCES}

1. $\quad$ Arnott, R. 2005. Fundamental Indexation. Financial Analyst Journal 61 (2), pp.83-100.

2. Bronars, S. G., and D. R. Deere, 1991, The threat of unionization, the use of debt, and the preservation of shareholder wealth, Quarterly Journal of Economics 106, 231-54.

3. Bronars, S. G, Deere, D. R, and J.S. Tracy. 1994. The effects of unions on firm behavior: An empirical analysis using firm-level data. Industrial Relations 33 (4) 426-52.

4. Danthine, J.P., and J.B. Donaldson. 2002. Labour relations and asset returns, Review of Economic Studies 69, 41-64.

5. Fama, E. F., and K.R. French. 1992. Cross-Section of Expected Stock Returns. The Journal of Finance, 47(2), 427-66.

6. Merz, M., and E. Yashiv. 2007. Labor and the market value of the firm, American Economic Review 97 (4), 1419-31.

7. Rosenberg, B., Reid, K., and R. Lanstein. 1985. Persuasive Evidence of Market Inefficiency. Journal of Portfolio Management, 11(3), 9-17.

8. Ruback, R. S., and M. Zimmerman. 1984. Unionization and Profitability: Evidence from the Capital Market. The Journal of Political Economy 92 (6), 1134-58.

9. $\quad$ Siegel, Jeremy. "The Noisy Market Hypothesis." Wall Street Journal. 6/14/2006, p. A14. 
NOTES 